OPEN ACCESS

Edited by:

Rosa Cortese,

University College London,

United Kingdom

Reviewed by:

Ermelinda De Meo,

San Raffaele Hospital (IRCCS), Italy

Giacomo Casella,

Thomas Jefferson University,

United States

*Correspondence:

Stefan J. Troche

stefan.troche@psy.unibe.ch

Specialty section:

This article was submitted to

Multiple Sclerosis and

Neuroimmunology,

a section of the journa

Frontiers in Neurology

Received: 24 June 2020

Accepted: 26 August 2020

Published: 20 October 2020

Citation:

Troche SJ, Kapanci T, Rammsayer TH,

Kesseler CPA, Häusler MG, Geis T,

Schimmel M, Elpers $C$, Kreth JH,

Thiels C and Rostásy K (2020) Interval

Timing in Pediatric Multiple Sclerosis:

Impaired in the Subsecond Range but

Unimpaired in the One-Second

Range. Front. Neurol. 11:575780.

doi: 10.3389/fneur.2020.575780

\section{Interval Timing in Pediatric Multiple Sclerosis: Impaired in the Subsecond Range but Unimpaired in the One-Second Range}

\author{
Stefan J. Troche ${ }^{1 *}$, Tugba Kapanci ${ }^{2}$, Thomas H. Rammsayer ${ }^{1}$, Carl P. A. Kesseler ${ }^{2}$, \\ Martin Georg Häusler ${ }^{3}$, Tobias Geis ${ }^{4}$, Mareike Schimmel ${ }^{5}$, Christiane Elpers ${ }^{6}$, \\ Jonas H. Kreth ${ }^{7}$, Charlotte Thiels ${ }^{8}$ and Kevin Rostásy ${ }^{9}$ \\ 1 Institute of Psychology, University of Bern, Bern, Switzerland, ${ }^{2}$ Department of Psychology and Psychotherapy, University of \\ Witten/Herdecke, Witten, Germany, ${ }^{3}$ Division of Neuropediatrics and Social Pediatrics, Department of Pediatrics, University \\ Hospital, Rheinisch-Westfälische Technische Hochschule Aachen, Aachen, Germany, ${ }^{4}$ Department of Pediatric Neurology, \\ Klinik St. Hedwig, University Children's Hospital Regensburg (Kinder-Universitätsklinik Ostbayern KUNO), Regensburg, \\ Germany, ${ }^{5}$ Pediatric Neurology, Children's Hospital, University Hospital Augsburg, Augsburg, Germany, ${ }^{6}$ Neuropediatric \\ Department, Children's University Hospital Muenster, Muenster, Germany, ${ }^{7}$ Department of Pediatric Neurology, Hospital for \\ Children and Adolescents, Klinikum Leverkusen, Leverkusen, Germany, ${ }^{8}$ Department of Pediatrics and Pediatric Neurology, \\ Ruhr University Bochum, Bochum, Germany, ${ }^{9}$ Pediatric Neurology, University of Witten/Herdecke, Children's Hospital \\ Datteln, Datteln, Germany
}

Background: For adult multiple sclerosis (MS) patients, impaired temporal processing of simultaneity/successiveness has been frequently reported although interval timing has been investigated in neither adult nor pediatric MS patients. We aim to extend previous research in two ways. First, we focus on interval timing (instead of simultaneity/successiveness) and differentiate between sensory-automatic processing of intervals in the subsecond range and cognitive processing of intervals in the one-second range. Second, we investigate whether impaired temporal information processing would also be observable in pediatric MS patients' interval timing in the subsecond and one-second ranges.

Methods: Participants were 22 pediatric MS patients and 22 healthy controls, matched for age, gender, and psychometric intelligence as measured by the Culture Fair Test 20-R. They completed two auditory interval-timing tasks with stimuli in the subsecond and one-second ranges, respectively, as well as a frequency discrimination task.

Results: Pediatric MS patients showed impaired interval timing in the subsecond range compared to healthy controls with a mean difference of the difference limen (DL) of $6.3 \mathrm{~ms}, 95 \% \mathrm{Cl}[1.7,10.9 \mathrm{~ms}]$ and an effect size of Cohen's $d=0.830$. The two groups did not differ significantly in interval timing in the one-second range (mean difference of the $\mathrm{DL}=26.9 \mathrm{~ms}, 95 \% \mathrm{Cl}[-14.2,67.9 \mathrm{~ms}]$, Cohen's $d=0.399)$ or in frequency discrimination (mean difference of the $\mathrm{DL}=0.4 \mathrm{~Hz}, 95 \% \mathrm{Cl}[-1.1,1.9 \mathrm{~Hz}]$, Cohen's $d=0.158$ ).

Conclusion: The results indicate that, in particular, the sensory-automatic processing of intervals in the subsecond range but not the cognitive processing of longer intervals is impaired in pediatric MS patients. This differential pattern of results is unlikely to be 
explained by general deficits of auditory information processing. A tentative explanation, to be tested in future studies, points to subcortical deficits in pediatric MS patients, which might also underlie deficits in speech and visuomotor coordination typically reported in pediatric MS patients.

Keywords: cognitive impairment, interval timing, pediatric multiple sclerosis (MS), neuropsychology, distinct timing hypothesis, temporal information processing

\section{INTRODUCTION}

Multiple sclerosis (MS) is an inflammatory neurological disease, which leads to demyelination and neuroaxonal injury of the central nervous system and, subsequently, to physical and cognitive impairments. In about $5 \%$ of MS patients, onset of the disease is before the age of 18 years (1), and age of onset plays a crucial role in individual differences in neurological and cognitive effects of MS (2). According to Charvet et al. (3), one third of pediatric MS patients suffer from cognitive impairment already in the early phase of the disease. In line with this observation, children and adolescents with MS suffer from substantial brain volume loss already at the time of the first event (4). Pediatric and adult MS patients seem to differ in their cognitive deficits (5), and a longitudinal cohort study demonstrates a more pronounced decline of information-processing efficiency for individuals with pediatric- than adult-onset MS, primarily at the age of about 30 (6). Probably due to the low prevalence of pediatric MS, the manifoldness of cognitive impairments is less well-investigated in pediatric compared to adult MS patients. For example, processing of temporal information has been reported to be impaired in adult MS patients but, to the best of our knowledge, has not been investigated in pediatric MS patients yet.

Temporal information processing does not represent a unitary concept but rather consists of distinct elementary temporal experiences [e.g., $(7,8)]$. Researchers interested in the functional relationship between temporal information processing and brain functioning have devoted particular attention to two elementary time experiences: (1) simultaneity and successiveness and (2) interval timing.

Investigations into simultaneity and successiveness are concerned with the size of the temporal interval between two or more events that is required for them to be perceived as separate events (successiveness) rather than fused as one event (simultaneity). Visual or auditory fusion thresholds, for example, represent an indicator of this type of temporal resolution power for central sensory information processing (9). Over the past six decades, a large number of clinical studies provide convincing evidence for MS patients' significantly impaired visual-temporal resolution ability as indicated by higher fusion thresholds compared to healthy controls (10-14). Although no auditory fusion studies in MS patients seem to exist, important clues for impaired auditory temporal resolution ability comes from a recent study by Valadbeigi et al. (15). As a tool for evaluating temporal resolution ability in MS patients, these authors assess gap detection thresholds. For this purpose, participants had to detect silent intervals ranging from 2 to $20 \mathrm{~ms}$ embedded in 6-s segments of white noise. MS patients showed significantly higher thresholds for gap detection than healthy controls, indicating impaired auditory temporal resolution performance in MS patients.

Interval timing, including time estimation and duration discrimination, refers to the accurate timing of events. Accurate timing plays a crucial role for motor processes (16), speech (17), and learning (18) as well as working memory functioning (19). Hence, interval timing can be considered a basic component of cognitive functioning of all sorts [cf. (20)]. Given the important role of timing processes for cognitive functions shown to be impaired in MS patients, it is very surprising that no studies on interval timing in pediatric MS patients seem to exist. The aim of the present study, therefore, was to investigate, for the first time, performance on interval timing tasks in MS patients by comparing a group of pediatric MS patients with a group of healthy controls matched for age, sex, and psychometric intelligence.

The so-called distinct timing hypothesis [cf. (21, 22)] suggests two dissociable mechanisms for the timing of extremely brief durations in the subsecond range and longer durations, respectively. More precisely, interval durations less than approximately $300-500 \mathrm{~ms}$ can be perceived directly due to sensory-automatic temporal processing, whereas the duration of longer intervals needs to be reconstructed by higher mental processes [cf. (22)]. To tap into performance differences between MS patients and healthy controls in both the sensory-automatic as well as the cognitive processes involved in interval timing, two auditory duration-discrimination tasks with base durations of 100 and $1,000 \mathrm{~ms}$, respectively, were applied in the present study. Furthermore, in order to control for more general, nontemporal, MS-related deficits in sensory transmission of acoustic stimuli [e.g., (23)], we also employed a frequency-discrimination task in addition to the two timing tasks.

\section{METHODS}

\section{Participants}

Twenty-three pediatric MS patients (19 females) participated in the present study. Their age ranged from 12 to 18 years $(M \pm S D$ : $15.6 \pm 1.9$ years $)$. Mean age at disease onset was $14.3( \pm 1.8)$ years, and the mean number of relapses was $2.61( \pm 1.03)$. Scores on the Expanded Disability Status Scale (EDSS; (24)) ranged from 0 to 6.5 with a mean score of $1.65( \pm 1.70)$, and their mean IQ was 97.43 ( \pm 9.37) according to Cattell's Culture Fair Test 20-R (CFT 20-R). Diagnoses were based on the recently revised McDonald 
criteria (25). Twenty pediatric MS patients were treated with Interferon, two with Glatirameracetat, and one was therapynaive. No patient received steroid treatment. Furthermore, no patient had clinical disease activity at the time of testing, and the attending doctors judged the clinical status of all participating patients as stable.

Previous research reveals that interval timing improves with increasing age of children and adolescents $(26,27)$ and that males might have lower discrimination thresholds than females (28). Furthermore, psychometric intelligence is positively related to performance on interval timing tasks (29) and has a differential effect on cognitive impairments due to MS (30). Therefore, the 23 MS patients were compared to 23 participants, out of a pool of 63 (neurologically and psychologically) healthy adolescents, matched for age, sex, and intelligence by means of a nearestneighbor matching algorithm (31). The algorithm determined 19 female and four male healthy controls with a mean age of $16.4( \pm$ $2.2)$ years and a mean IQ of $99.4( \pm 10.7)$. They did not differ significantly from MS patients in age, $t(43.007)=1.373, p=$ $0.177, d=0.405$, and intelligence test scores, $t(43.210)=0.658$, $p=0.514, d=0.194$.

All MS patients and healthy controls reported normal hearing and normal or corrected-to-normal vision. All participants and the parents of participants younger than 18 years were informed about the study protocol and signed informed consent prior to the study. The study was approved by the local ethics committee of the University of Witten/Herdecke (No. 173/2016).

\section{Assessment of Depression}

With the German Depression Inventory for Children and Adolescents [DIKJ; (32)], the severity of major depression symptoms was measured. For each of the 29 items, children chose the most applicable statement out of three alternatives. Stiensmeier-Pelster et al. (32) report high reliability coefficients ranging between Cronbach's $\alpha=0.87$ and 0.92 .

\section{Assessment of Fatigue}

With the 21 items of the German Modified Fatigue Impact Scale [MFIS; (33)], MS patients and healthy controls self-reported the severity with which fatigue affected physical, cognitive, and psychosocial aspects of their lives. According to Fisk et al. (33), the internal consistency is $\alpha=0.81$. One MS patient did not respond to one and another patient did not respond to two MFIS items. Their sum scores were estimated on the basis of the other 20 or 19 items, respectively.

\section{Expanded Disability Status Scale (EDSS)}

The severity of MS-related disability in patients at the time of data collection was assessed by means of the EDSS (24). Scores could range from 0 to 10 .

\section{Experimental Tasks}

The three experimental tasks employed in the present study have previously been validated for investigating interval timing and frequency discrimination in children and adolescents $(26,27)$. A Lenovo notebook (L540) was used with a 15" monitor as well as an external audio interface (Steinberg, UR22 MKII) and headphones (Sennheisser HDA300). Stimuli were presented by E-prime 2.0 experimental software and responses were given on a Cedrus ${ }^{\circledR}$ keyboard (RB-840).

\section{Interval Timing in the Subsecond Range}

Stimuli were white noise bursts presented at an intensity of 68 $\mathrm{dB}$. The task consisted of 64 trials. Each trial consisted of a constant 100-ms standard interval and a variable comparison interval presented with an interstimulus interval (ISI) of $900 \mathrm{~ms}$. The order of standard and comparison intervals within a trial was balanced and randomized across trials. The participant's task was to decide whether the first or the second stimulus was of longer duration by pressing one of two designated keys. Visual feedback was given after the response on the monitor for $1,500 \mathrm{~ms}(\mathrm{a}$ " + " after a correct and a "-" after an incorrect response). After an intertrial interval of $600 \mathrm{~ms}$, the next trial started.

The 64 trials were assigned to two interleaved series. In one series, the comparison (with an initial duration of $65 \mathrm{~ms}$ ) was shorter than the standard interval. In the other series, the comparison (with an initial duration of $135 \mathrm{~ms}$ ) was longer than the standard interval. Using the adaptive weighted up-down method (34), the difference between the comparison and standard intervals decreased after a correct response $(5 \mathrm{~ms}$ in the first six trials, $3 \mathrm{~ms}$ in the following trials) and increased after an incorrect response $(15 \mathrm{~ms}$ in the first six trials, $9 \mathrm{~ms}$ in the following trials). With this step-size ratio of $1: 3$, the two series converged to the $25 \%$ difference threshold (series with comparison interval shorter than standard) and the 75\% difference threshold (series with comparison interval longer than standard), which were estimated from the last 20 trials of each series. The difference limen [DL; (35)] was computed as individual performance score, which refers to half the difference of the $75 \%$ and $25 \%$ difference thresholds. With this measure, superior performance on duration discrimination is indicated by smaller DL values.

\section{Interval Timing in the One-Second Range}

Hardware and software as well as the number of trials and the experimental procedure were the same as in the duration discrimination task in the range of milliseconds. The only differences were that the standard interval had a duration of $1,000 \mathrm{~ms}$ and the initial comparison intervals of 500 and $1,500 \mathrm{~ms}$ in the two series for the estimation of the $25 \%$ and the $75 \%$ difference thresholds. Step-sizes of the change of the comparison interval were $25 \mathrm{~ms}$ after a correct $(100 \mathrm{~ms}$ in the first six trials) and $75 \mathrm{~ms}$ after an incorrect response $(300 \mathrm{~ms}$ in the first six trials). Again, the DL was computed as individual performance score.

\section{Frequency Discrimination}

The experimental procedure was the same as for the durationdiscrimination tasks with the following exceptions. All stimuli were sine wave tones of $500 \mathrm{~ms}$ duration and presented with an intensity of $68 \mathrm{db}$. Each trial consisted of a standard tone with a frequency of $440 \mathrm{~Hz}$ and a comparison tone with a variable frequency and initial values of $438 \mathrm{~Hz}$ in the series converging to the $25 \%$ difference threshold and $442 \mathrm{~Hz}$ in the series converging 
to the $75 \%$ difference threshold. The step sizes were $0.3 \mathrm{~Hz}(0.5 \mathrm{~Hz}$ in the first six trials) after a correct response and $0.9 \mathrm{~Hz}(1.5 \mathrm{~Hz}$ in the first six trials) after an incorrect response. The ISI was $500 \mathrm{~ms}$. The DL was computed as individual performance score.

\section{Assessment of Intelligence}

The CFT 20-R (36), composed of three subtests (series, classifications, matrices) with 27 items, respectively, and one subtest (topologies) with 20 items, was administered individually and lasted about $1 \mathrm{~h}$. The reliability of the CFT 20-R is high with $r_{\mathrm{tt}}=0.96$. Originally, the CFT was developed to assess fluid intelligence as an abstract reasoning ability independent from crystallized intelligence, which refers to language- and knowledge-related abilities. Thus, rather specific language deficits in MS patients do not (or only marginally) bias the assessment of intelligence by means of the CFT. The high correlation between CFT scores and general intelligence underlines its adequacy to measure an individual's overall cognitive functioning (37). The version CFT 20-R (36) is validated for adults and children and comprises fine-grained age-stratified IQ norms for children older than 6 years, adolescents, and adults. As a dependent variable, correct responses across all subtests were added to raw scores and transformed to age-stratified IQ equivalents.

\section{Time Course of the Study}

The session started with verbal and written information about the study and signing informed consent by the participants and/or their parents followed by the administration of DIKJ and MFIS. The experimental part of the study started with two tasks, which lasted about $25 \mathrm{~min}$ and are reported in detail by Kapanci et al. (38). After a break of $15 \mathrm{~min}$, the three discrimination tasks were presented in counterbalanced order. Each task lasted about $10 \mathrm{~min}$. After another short break, participants completed the CFT 20-R. The total session lasted about $120 \mathrm{~min}$.

\section{RESULTS}

An initial outlier detection revealed that discrimination thresholds in the interval timing task in the second range of one female MS patient and one female healthy control were more than three standard deviations above the mean of the respective group. These two participants were excluded from further analyses. Descriptive data as well as appropriate $t$-tests for age, IQ, depression, and fatigue are provided in Table 1 for the remaining $22 \mathrm{MS}$ patients and 22 healthy controls of the final sample. MS patients and healthy controls did not differ significantly in age and IQ. Furthermore, no significant differences were obtained regarding symptoms of depression and fatigue.

The main outcome variables of the present study were DL values in the two interval timing tasks (with stimuli in the subsecond and in the second range) and in the frequency discrimination task. Differences in discrimination performance, as indicated by DL values, between pediatric MS patients and healthy controls were investigated by means of three $t$-tests. In order to avoid alpha inflation, alpha was Bonferroni adjusted to $\alpha=0.017$. Descriptive statistics, results of $t$-tests, and effect sizes
(Cohen's $d$ ) are reported in Table 1. As can be seen from Figure 1, MS patients differed significantly from healthy controls in their performance on neither the frequency discrimination task (mean difference in $\mathrm{DL}=0.4 \mathrm{~Hz} ; 95 \%[-1.1,1.9 \mathrm{~Hz}]$ ) nor the interval timing task with stimulus durations in the one-second range (mean difference in DL $=26.9 \mathrm{~ms}$; 95\% CI $[-14.2,67.9 \mathrm{~ms}]$ ). For interval timing in the subsecond range, however, mean DL was significantly larger in pediatric MS patients than in healthy controls. The mean difference in DL was $6.3 \mathrm{~ms}$ with the $95 \%$ confidence interval not including zero [1.7, $10.9 \mathrm{~ms}]$. This result indicated worse performance in pediatric MS patients compared to healthy controls as they needed larger differences between two durations in the subsecond range to correctly identify the longer one.

It should be noted that the same pattern of results was obtained when only the data of the 18 female participants in each group were analyzed. Furthermore, neither in MS patients nor in healthy controls was age significantly correlated with performance on the interval timing or the frequency discrimination tasks. Given that the two groups did not differ in age, a systematic influence of age on the above reported results is unlikely.

\section{DISCUSSION}

The aim of the present study was to investigate possible impairments of interval timing in pediatric MS patients using two auditory duration discrimination tasks that focused on interval timing in the subsecond and one-second ranges, respectively. Compared to healthy controls, MS patients showed impaired interval timing in the subsecond range but no significant differences in the one-second range. These differences in the subsecond range are unlikely to be based on general deficits of auditory information processing as the auditory demands regarding the duration discrimination task in the one-second range were virtually identical. Moreover, there were no differences in the frequency discrimination thresholds between MS patients and healthy controls. Due to the matching procedure, differences in age, sex, and psychometric intelligence can also be excluded to explain MS patients' impaired interval timing in the subsecond range.

Our findings expand previous results on impaired perception of simultaneity and successiveness in adult MS patients in two ways. First, timing deficits do not only occur in adult but also in pediatric MS patients. Second, in addition to judgments of simultaneity and successiveness as previously reported (13-15) MS also affects interval timing in the subsecond range-at least in pediatric patients.

Our findings support the distinct timing hypothesis $(21,22)$, which suggests two dissociable mechanisms underlying the timing of extremely brief durations in the subsecond range and longer durations in the second range. It appears that the sensoryautomatic temporal processing of extremely brief durations below $300-500 \mathrm{~ms}$ is substantially impaired in pediatric MS patients, whereas cognitively mediated temporal processing of longer durations is less affected. 
TABLE 1 | Mean (M) and standard deviation (SD) of age, normed CFT 20-R IQ scores, fatigue (MFIS), and depression scores (DIKJ) as well as difference limen (DL) in the two interval timing tasks and the frequency discrimination task for 22 pediatric MS patients and 22 healthy controls.

\begin{tabular}{|c|c|c|c|c|c|c|c|c|}
\hline & \multicolumn{2}{|c|}{ Pediatric MS } & \multicolumn{2}{|c|}{ Healthy controls } & \multirow[t]{2}{*}{$t$} & \multirow[t]{2}{*}{$d f$} & \multirow[t]{2}{*}{$\boldsymbol{P}$} & \multirow[t]{2}{*}{$d$} \\
\hline & $M$ & $S D$ & $M$ & $S D$ & & & & \\
\hline Age [years] & 15.5 & 1.9 & 16.5 & 2.1 & -1.644 & 41.635 & 0.108 & -0.496 \\
\hline IQ & 97.1 & 9.4 & 99.5 & 11.0 & -0.781 & 41.083 & 0.440 & -0.235 \\
\hline MFIS & 30.7 & 18.1 & 23.5 & 10.5 & 1.632 & 33.623 & 0.112 & 0.492 \\
\hline DIKJ & 13.2 & 6.0 & 12.8 & 6.3 & 0.246 & 41.875 & 0.807 & 0.074 \\
\hline $\mathrm{DL}$ of interval timing in the millisecond range [ms] & 19.8 & 8.3 & 13.6 & 6.8 & 2.753 & 40.308 & 0.009 & 0.830 \\
\hline DL of interval timing in the second range [ms] & 166.6 & 67.4 & 139.7 & 67.4 & 1.322 & 42.000 & 0.193 & 0.399 \\
\hline $\mathrm{DL}$ of frequency discrimination $[\mathrm{Hz}]$ & 6.4 & 2.0 & 6.0 & 2.9 & 0.525 & 37.756 & 0.603 & 0.158 \\
\hline
\end{tabular}

Also reported are t-tests and corresponding effect sizes (Cohen's d).

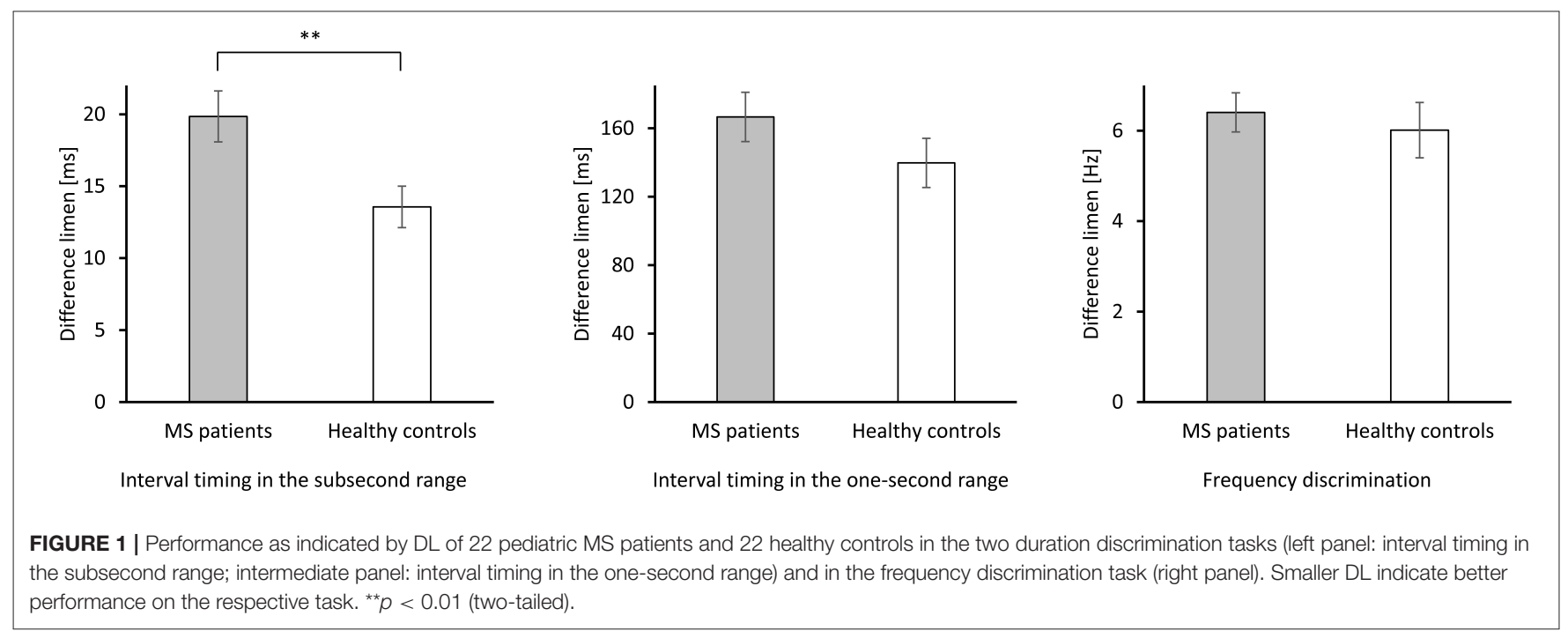

As depicted in Figure 1, MS patients show a performance decrement in both duration discrimination tasks compared to healthy controls. We cannot rule out that, in a larger sample, the difference in interval timing in the one-second range between MS patients and healthy controls might also have become statistically significant. The effect size, however, was more than twice as large for the interval timing in the subsecond compared to the one-second range. Thus, the sensory-automatic processes underlying the timing of intervals in the subsecond range seem to be particularly vulnerable to degenerative changes in the brain associated with MS.

There is good empirical evidence for the notion that distinct but partly overlapping neural networks underlie interval timing in the sub- and suprasecond range. In the meta-analysis by Wiener et al. (39), activation in the inferior frontal cortex, supplementary motor areas, precental gyrus, parietal lobe, insular cortex, claustrum, and putamen was related to both sub- and suprasecond timing. Particularly pronounced activation during temporal processing in the suprasecond range was found for the (right) prefrontal brain areas [see also (40)]. For timing in the subsecond range, specific activation was primarily identified in subcortical areas, such as the cerebellum $(39,41)$, thalamus, and striatal parts of the basal ganglia $(39,42)$ as well as some neocortical areas (e.g., the right inferior parietal lobe). Most interestingly, MS-related deficits in subcortical areas have been reported even at an early stage of the disease (43) and more frequently in pediatric than adult patients (44). Hence, a tentative explanation of the present findings might be that pediatric MS patients' impaired timing performance in the subsecond range is indicative of deficits in subcortical brain areas.

Previous research shows that accurate timing in the subsecond range plays an important role for motor coordination and visuomotor integration (16) and for speech perception and production (17) as well as speed of information processing (29). Against this background, it is particularly interesting that pediatric MS patients process information more slowly than healthy controls (5), have more problems integrating visuomotor information $(1,3,45-47)$, and have deficits in fine motor coordination (46). Moreover, pediatric MS patients more frequently show receptive and expressive language deficits $(1,45,47,48)$. Thus, it would be promising for future research to investigate to what degree pediatric MS patients' timing deficits-as observed in the present study-is functionally related to their commonly observed deficits in motor coordination, 
processing speed, and speech. Such results would contribute to a better understanding of the neurocognitive mechanisms underlying MS patients' health-related restrictions observed in everyday life.

In sum, pediatric MS patients in the present study show impaired performance on interval timing in the subsecond range compared to healthy controls. This impairment is unlikely to be explained by auditory deficits because no performance differences between the two groups could be established for interval timing in the one-second range and frequency discrimination. As most brain areas specifically affecting interval timing in the subsecond range are subcortical, a tentative, but plausible explanation might point to subcortical alterations in the present sample of pediatric MS patients. Timing in the subsecond range is important for many daily life activities, such as visuomotor coordination or speech commonly impaired in pediatric MS patients. If future studies establish functional relationships between MS-related deficits in interval timing in the subsecond range and these daily life activities, the investigation of interval timing in the subsecond range might be a promising approach to better understand the underlying causes of these deficits.

\section{REFERENCES}

1. Banwell BL, Anderson PE. The cognitive burden of multiple sclerosis in children. Neurology. (2005) 64:891-4. doi: 10.1212/01.WNL.0000152896.35341.51

2. Waldman A, Ghezzi A, Bar-Or A, Miaeloff Y, Tardieu M, Banwell B. Multiple sclerosis in children: an update on clinical diagnosis, therapeutic strategies, and research. Lancet Neurol. (2014) 13:936-48. doi: 10.1016/S1474-4422(14)70093-6

3. Charvet LE, O'Donnell EH, Belman AL, Chitnis T, Ness JM, Parrish J, et al. Longitudinal evaluation of cognitive functioning in pediatric multiple sclerosis: report from the US Pediatric Multiple Sclerosis Network. Multiple Sclerosis J. (2014) 20:1502-10. doi: 10.1177/1352458514527862

4. Bartels F, Nobis K, Cooper G, Wendel E, Cleaveland R, Bajer-Kornek B, et al. Childhood multiple sclerosis is associated with reduced brain volumes at first clinical presentation and brain growth failure. Multiple Sclerosis J. (2019) 25:927-36. doi: 10.1177/1352458519829698

5. Ekmekci O. Pediatric Multiple Sclerosis and cognition: a review of clinical, neuropsychologic, and neuroradiologic features. Behav Neurol. (2017) 2017:1463570. doi: 10.1155/2017/1463570

6. McKay KA, Manouchehrinia A, Berrigan L, Fisk JD, Olsson T, Hillert J. Long-term cognitive outcomes in patients with pediatric-onset vs. adult-onset multiple sclerosis. JAMA Neurol. (2019) 76:1028-34. doi: 10.1001/jamaneurol.2019.1546

7. Block RA. Cognitive Models of Psychological Time. Hillsdale, NJ: Lawrence Erlbaum. (1990).

8. Pöppel E. Time perception. In: R Held, HW Leibowitz, HL Teuber, editor. Handbook of Sensory Physiology. Berlin: Springer. (1978). p. 713-29. doi: 10.1007/978-3-642-46354-9_23

9. Robin DA, Royer FL. Auditory temporal processing: two-tone cutter fusion and a model of temporal integration. J Acoustical Soc Am. (1987) 82:1207-17. doi: 10.1121/1.395257

10. Daley ML, Swank RL, Ellison CM. Flicker fusion thresholds in multiple sclerosis: a functional measure of neurological damage. Archiv Neurol. (1979) 36:292-5. doi: 10.1001/archneur.1979.00500410070010

11. Parsons OA, Miller PN. Flicker fusion thresholds in multiple sclerosis. AMA Archiv Neurol Psychiatry. (1957) 77:134-9. doi: 10.1001/archneurpsyc.1957.02330320032004

\section{DATA AVAILABILITY STATEMENT}

The raw data supporting the conclusions of this article will be made available by the authors, without undue reservation.

\section{ETHICS STATEMENT}

The studies involving human participants were reviewed and approved by local ethic committee of the University of Witten/Herdecke (No. 173/2016). Written informed consent to participate in this study was provided by the participants' legal guardian/next of kin.

\section{AUTHOR CONTRIBUTIONS}

ST, TK, and KR conceptualized and planned the experiments. ST, TK, CK, MH, TG, MS, CE, JK, CT, and KR carried out the experiments. ST, TK, and CK contributed to sample preparation. ST, TK, CK, and TR contributed to the interpretation of the results. ST took the lead in writing the manuscript. All authors were involved in recruiting participants, provided critical feedback, and revised the manuscript.

12. Titcombe AF, Willison RG. Flicker fusion in multiple sclerosis. J Neurol Neurosurg Psychiatry. (1961) 24:260-5. doi: 10.1136/jnnp.24.3.260

13. Vleugels L, van Nunen A, Lafosse C, Ketelaer P, Vandenbussche E. Temporal and spatial resolution in foveal vision of multiple sclerosis patients. Vis Res. (1998) 38:2987-97. doi: 10.1016/S0042-6989(98)0 0010-8

14. Patterson VH, Foster DH, Heron JR, Mason RJ. Multiple sclerosis: luminance threshold and measurements of temporal characteristics of vision. Archiv Neurol. (1981) 38:687-9. doi: 10.1001/archneur.1981.005101100 47005

15. Valadbeigi A, Weisi F, Rohbakhsh N, Rezaei M, Heidari A, Rasa A. Central auditory processing and word discrimination in patients with multiple sclerosis. Eur Archiv Oto-Rhino-Larnygol. (2014) 271:2891-6. doi: 10.1007/s00405-013-2776-6

16. Chen Y-H, Cesari P. Elite athletes refine their internal clocks. Motor Control. (2015) 19:90-101. doi: 10.1123/mc.2013-0081

17. Kotz S, Schwartze M. Motor-timing and sequencing in speech production: a general-purpose framework. In: G Hickok, SL Small, editors. Neurobiology of Language. Amsterdam: Academic Press. (2016). p. 717-24. doi: 10.1016/B978-0-12-407794-2.00057-2

18. Kirkpatrick K, Balsam PD. Associative learning and timing. Curr Opin Behav Sci. (2016) 8:181-5. doi: 10.1016/j.cobeha.2016.02.023

19. Troche SJ, Rammsayer TH. The influence of temporal resolution power and working memory capacity on psychometric intelligence. Intelligence. (2009) 37:479-86. doi: 10.1016/j.intell.2009.06.001

20. Petter EA, Lusk NA, Hesslow G, Meck WH. Interactive roles of the cerebellum and striatum in sub-second and supra-second timing: support for an initiation, continuation, adjustment, and termination (ICAT) model of temporal processing. Neurosci Biobehav Rev. (2016) 71:739-55. doi: 10.1016/j.neubiorev.2016.10.015

21. Rammsayer TH, Troche SJ. In search of the internal structure of the processes underlying interval timing in the sub-second and the second range: a confirmatory factor analysis approach. Acta Psychol. (2014) 147:68-74. doi: 10.1016/j.actpsy.2013.05.004

22. Rammsayer $\mathrm{TH}$, Ulrich R. Elaborative rehearsal of nontemporal information interferes with temporal processing of durations in the range of seconds but not milliseconds. Acta Psychol. (2011) 137:127-33. doi: 10.1016/j.actpsy.2011.03.010 
23. Mustillo P. Auditory deficits in Multiple Sclerosis. Audiology. (1984) 23:14564. doi: 10.3109/00206098409072831

24. Kurtzke JF. Rating neurologic impairment in multiple sclerosis: an expanded disability status scale (EDSS). Neurology. (1983) 33:1444-52. doi: 10.1212/WNL.33.11.1444

25. Thompson AJ, Banwell BL, Barkhof F, et al. Diagnosis of multiple sclerosis: 2017 revisions of the McDonald criteria. Lancet Neurol. (2018) 17:162-73. doi: 10.1016/S1474-4422(17)30470-2

26. Troche SJ, Bellmann-Knieps P, Rammsayer TH. Prediction of scholastic performance by psychophysical indicators of temporal resolution power. Eur J Psychol. (2008) 4:4. doi: 10.5964/ejop.v4i4.441

27. Voelke AE, Troche SJ, Rammsayer TH, Wagner FL, Roebers CM. Sensory discrimination, working memory and intelligence in 9-year-old and 11-yearold children. Infant Child Dev. (2013) 22:523-38. doi: 10.1002/icd.1803

28. Rammsayer TH, Troche SJ. Sex differences in the processing of temporal information in the sub-second range. Personal Individual Diff. (2010) 49:9237. doi: 10.1016/j.paid.2010.07.031

29. Pahud O, Rammsayer TH, Troche SJ. Putting the temporal resolution power (TRP) hypothesis to a critical test: is the TRP-g relationship still more fundamental than an optimized relationship between speed of information processing and g? Intelligence. (2018) 70:52-60. doi: 10.1016/j.intell.2018.08.002

30. Amato MP, Prestipino E, Bellinvia A, Niccolai C, Razzolini L, Pastò L, et al. Cognitive imparment in multiple sclerosis: an exploratory analysis of environmental and lifestyle risk factors. PLoS ONE. (2019) 14:e0222929. doi: 10.1371/journal.pone.0222929

31. Ho DE, Imai K, King G, Stuart EA. MatchIt: nonparametric preprocessing for parametric causal inference. J Statist Softw. (2011) 42:1-28. doi: 10.18637 /jss.v042.i08

32. Stiensmayer-Pelster J, Schürmann M, Duda K. Depressionsinventar für Kinder und Jugendliche (DIKJ). [Depression Inventory for Children and Adolescents]. Göttingen: Hogrefe. (1989).

33. Fisk JD, Ritvo PG, Ross L, Haase DA, Marrie TJ, Schlech WF. Measuring the functional impact of fatigue: initial validation of the fatigue impact scale. Clin Infect Dis. (1994) 18:79-83. doi: 10.1093/clinids/18.Supplement_1.S79

34. Kaernbach C. Simple adaptive testing with the weighted up-down method. Perception Psychophys. (1991) 49:227-9. doi: 10.3758/BF03214307

35. Luce RD, Galanter E. Discrimination. In: RD Luce, RR Bush, E Galanter, editors. Handbook of Mathematical Psychology. New York, NY: Wiley. (1963). p. 191-243.

36. Weiß RH. CFT20-R-Grundintelligenztest Skala 2 [The Culture Fair Intelligence Test, Scale 2]. Göttingen: Hogrefe (2006).

37. Johnson W, te Nijenhuis J, Bouchard TJ Jr. Still just 1 g: consistent results from five test batteries. Intelligence. (2008) 36:81-95. doi: 10.1016/j.intell.2007.06.001

38. Kapanci T, Rostásy K, Häusler MG, Geis T, Schimmel M, Elpers C, et al. Evaluating the relationship between psychometric intelligence and cognitive functions in paediatric multiple sclerosis. Multiple Sclerosis J. (2019) 2019:1-9. doi: $10.1177 / 2055217319894365$
39. Wiener $\mathrm{M}$, Turkeltaub $\mathrm{P}$, Coslett $\mathrm{HB}$. The image of time: a voxel-wise meta-analysis. NeuroImage. (2010) 49:1728-40. doi: 10.1016/j.neuroimage.2009.09.064

40. Lewis PA, Miall RC. A right hemispheric prefrontal system for cognitive time measurement. Behav Process. (2006) 71:226-34. doi: 10.1016/j.beproc.2005.12.009

41. Hayashi MJ, Kantele M, Walsh V, Carlson S, Kanai R. Dissociable neuroanatomical correlates of subsecond and suprasecond time perception. J Cognit Neurosci. (2014) 26:1685-93. doi: 10.1162/jocn_a_ 00580

42. Lewis PA, Miall RC. Distinct systems for automatic and cognitively controlled time measurement: evidence from neuroimaging. Curr Opin Neurobiol. (2003) 13:250-5. doi: 10.1016/S0959-4388(03)00036-9

43. Crespy L, Zaaraoui W, Lemaire M, Rico A, Faivre A, Reuter F, et al. Prevalence of grey matter pathology in early Multiple Sclerosis assessed by magnetization transfer ratio imaging. PLoS ONE. (2011) 6:e24969. doi: 10.1371/journal.pone.0024969

44. MacAllister WS, Christodoulou C, Milazzo M, Preston TE, Serafin D, Krupp LB, et al. Pediatric multiple sclerosis: what we know and where are we headed? Child Neuropsychol. (2013) 19:1-22. doi: 10.1080/09297049.2011. 639758

45. Till C, Ghassemi R, Aubert-Broche B, Kerbrat A, Collins DL, Narayanan $S$, et al. MRI correlates of cognitive impairment in childhood-onset multiple sclerosis. Neuropsychology. (2011) 25:319-32. doi: 10.1037/a00 22051

46. Julian L, Serafin D, Charvet L, Ackerson J, Benedict R, Braaten E, et al. Cognitive impairment occurs in children and adolescents with multiple sclerosis: results from a United States network. J Child Neurol. (2013) 28:1027. doi: 10.1177/0883073812464816

47. Till C, Racine N, Araujo D, Narayanan S, Collins DL, Aubert-Broche B, et al. Changes in cognitive performance over a 1-year period in children and adolescents with multiple sclerosis. Neuropsychology. (2013) 27:210-9. doi: $10.1037 / \mathrm{a} 0031665$

48. MacAllister WS, Belman AL, Milazzo M, Weisbrot DM, Christodoulou C, Scherl WF, et al. Cognitive functioning in children and adolescents with multiple sclerosis. Neurology. (2005) 64:1422-5. doi: 10.1212/01.WNL.0000158474.24191.BC

Conflict of Interest: The authors declare that the research was conducted in the absence of any commercial or financial relationships that could be construed as a potential conflict of interest.

Copyright (C) 2020 Troche, Kapanci, Rammsayer, Kesseler, Häusler, Geis, Schimmel, Elpers, Kreth, Thiels and Rostásy. This is an open-access article distributed under the terms of the Creative Commons Attribution License (CC BY). The use, distribution or reproduction in other forums is permitted, provided the original author(s) and the copyright owner(s) are credited and that the original publication in this journal is cited, in accordance with accepted academic practice. No use, distribution or reproduction is permitted which does not comply with these terms. 